\title{
Effects of Locus Coeruleus Activation on Electroencephalographic Activity in Neocortex and Hippocampus
}

\author{
Craig W. Berridge and Stephen L. Foote \\ Department of Psychiatry, School of Medicine, University of California at San Diego, La Jolla, California 92093
}

\begin{abstract}
Experiments were conducted to examine the hypothesis that increased neuronal discharge activity of noradrenergic neurons of the locus coeruleus (LC) above resting discharge rates can alter forebrain electroencephalographic (EEG) activity. Small infusions (70-135 $\mathrm{nl}$ ) of the cholinergic agonist bethanechol within $500 \mu \mathrm{m}$ of the LC were used to activate this nucleus reversibly in halothane-anesthetized rats. A combined recording-infusion probe allowed verification of this electrophysiological activation. Simultaneously, EEG actlvity was recorded from sites in the frontal cortex and hippocampus and subjected to power-spectrum analyses. The findings were (1) LC activation was consistently followed, within 5 to $\mathbf{3 0} \mathrm{sec}$, by a shift from low-frequency, high-amplitude to high-frequency, low-amplitude EEG activity in frontal neocortex and by the appearance of intense $\theta$-rhythm in the hippocampus; (2) forebrain EEG changes followed LC activation with similar latencies whether infusions were made lateral or medial to the LC; (3) infusions placed outside the immediate vicinity of the LC were not followed by these forebrain EEG effects; (4) following infusion-induced activation, forebrain EEG returned to preinfusion patterns with about the same time course as the recovery of LC activity (10-20 $\mathrm{min}$ for complete recovery). These infusion-induced effects on EEG activity were blocked or severely attenuated by pretreatment with the $\alpha_{2}$-agonist clonidine, which inhibits LC discharge and norepinephrine release, or the $\beta$-antagonist propranolol. These observations indicate that enhanced LC discharge activity is the crucial mediating event for the infusion-induced changes in forebrain EEG activity observed under these conditions and suggest that $L C$ activation may be sufficient to induce EEG signs of cortical and hippocampal activation.
\end{abstract}

Currently available cvidence indicates that multiple brainstem systems participate in the control of processes such as arousal and alerting. For example, the involvement of brainstem cholinergic and serotonergic nuclei in the activation of EEG is supported by electrophysiological and pharmacological studies (Vanderwolf, 1988; Steriade et al., 1990). A number of obser-

Received Feb. 15, 1991; revised May 7, 1991; accepted May 8, 1991.

This research was supported by a grant from the Air Force Office of Scientific Research, U.S. Public Health Service Grant MH40008, and the MacArthur Foundation. We thank Drs. Joanne Carlson, Gyorgy Buzsaki, and Lynne Adams for helpful technical advice.

Correspondence should be addressed to Dr. Craig W. Berridge, Department of Psychiatry (0603), 9500 Gilman Drive, University of California at San Diego, La Jolla, CA 92093.

Copyright (C) 1991 Society for Neuroscience $0270-6474 / 91 / 113135-11 \$ 05.00 / 0$ vations suggest that the noradrenergic nucleus, locus coeruleus (LC), is also involved in such processes. Many anatomical and physiological characteristics of the LC-noradrenergic system, including the ability of norepinephrine (NE) to enhance stimulus-elicited responses in target neurons and the massively divergent efferent projections of this system, are compatible with this hypothesis (reviewed in Foote et al., 1983; Foote and Morrison, 1987). Consistent with these observations, $\alpha_{2}$-adrenergic agonists, which reduce LC neuronal discharge activity and inhibit NE release, have sedative effects (Laverty and Taylor, 1969; Fink and Irwin, 1981; Itil and Itil, 1983), whereas infusions of NE intracerebroventricularly or into forebrain sites induce behavioral activation (Segal and Mandell, 1970; Flicker and Geyer, 1982).

LC neurons exhibit enhanced discharge rates shortly before and during periods of arousal as indicated by behavioral and forebrain EEG measures (Hobson et al., 1975; Foote et al., 1980; Aston-Jones and Bloom, 1981), suggesting a possible causal link between enhanced LC/NE activity and EEG activation (Foote et al., 1980; Aston-Jones and Bloom, 1981). However, pharmacological and lesion studies have provided mixed support for this hypothesis (for review, see Vanderwolf and Robinson, 1981). For example, 6-hydroxydopamine (6-OHDA)-induced depletion of brain NE or electrical destruction of the LC decreased the incidence of low-amplitude, high-frequency EEG activity in some studies (Jouvet, 1972; Jones et al., 1973; Lidbrink and Fuxe, 1973; Lidbrink, 1974), whereas in others such treatments did not affect the incidence of episodes of EEG activation or the proportion of the day spent in the waking state (Jones et al., 1977; for review, see Vanderwolf and Robinson, 1981). Such contradictory results could be related to compensatory mechanisms that act to minimize the functional consequence of noradrenergic-specific lesions (Diaz et al., 1978; U'Prichard et al., 1980; Berridge and Dunn, 1990). Consistent with this, Lidbrink (1974) observed time-dependent effects of 6-OHDA lesions of the dorsal noradrenergic bundle on EEG activity; the lesions induced an increase in slow-wave activity and synchronization that disappeared approximately $7 \mathrm{~d}$ following the lesion.

Unfortunately, the two techniques typically used to activate brain nuclei acutely, electrical stimulation and local infusions, are not well suited for application to the LC. Electrical stimulation of the LC poses problems due to the small size of the $L C$, the close proximity of other nuclei involved in the regulation of the EEG, and the concomitant activation of fibers of passage. Local infusion generally relies on stereotaxic placement of an infusion needle. The small size of the LC makes the consistent placement of such a needle within or immediately adjacent to this nucleus virtually impossible. Consequently, large infusion 
Figure 1. Schematic depiction of experimental paradigm. A recording/infusion probe was used to record LC neuronal impulse activity before, during, and after infusions of bethanechol into peri-LC sites. These infusions activated LC neurons and, presumably, their efferent projections to hippocampus, neocortex, reticular formation, thalamic nuclei, and many other sites. EEG recordings were obtained simultaneously from frontal cortex (bipolar) and hippocampus (monopolar).

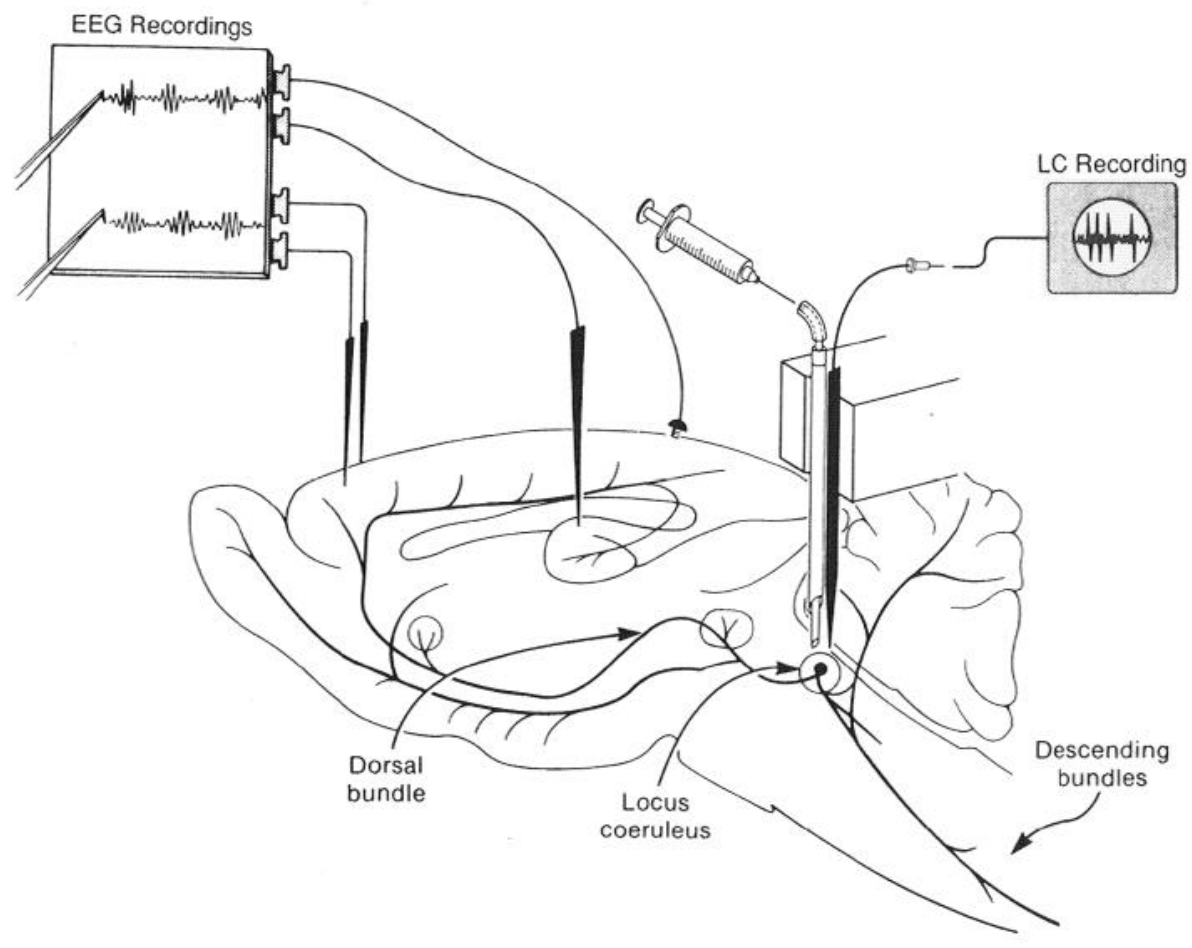

volumes, which spread over large areas, are necessitated to guarantee spread of the infusion to the LC.

We have previously described a method for the selective, acute, potent, and verifiable activation of the LC (Adams and Foote, 1988). This technique utilizes electrophysiological recordings to enable placement of infusions of the cholinergic agonist carbamyl- $\beta$-methyl choline chloride (bethanechol) within 150-500 $\mu \mathrm{m}$ of the nucleus. These infusions typically activate LC neurons to rates three to five times their basal discharge rates. The close proximity of the infusion site allows the use of small volumes that greatly limit the spread of the infusion to other brainstem structures while at the same time not damaging the LC. Importantly, this technique provides verification and allows quantification of the $\mathrm{LC}$ activation, and permits analysis of the temporal relationship between the onset and offset of LC activation and any observed physiological effects. Using this approach, the present study examined the effects of LC activation on EEG activity in cortical and hippocampal sites.

\section{Materials and Methods}

Animals and surgery. Male Sprague-Dawley rats weighing 250-350 gm were anesthetized with halothane using a face mask. A tracheotomy was then performed, and halothane $(0.75-1.25 \%$ in air) was administered via this route for the duration of the experiment. The animal was placed in a stereotaxic instrument with the incisor bar set $11.5 \mathrm{~mm}$ below the ear bars. Body temperature was maintained at $36-38^{\circ} \mathrm{C}$.

Clonidine and propranolol administration. Clonidine $(50 \mu \mathrm{g} / \mathrm{ml}, 50$ $\mu \mathrm{g} / \mathrm{kg}$; Sigma Chemical Co.) dissolved in saline was administered through a lateral tail vein 2 min prior to initiation of peri-LC bethanechol infusion. DL-Propranolol (Sigma Chemical Co.) was dissolved in saline containing $2 \%$ Pontamine sky blue and was administered into the contralateral lateral ventricle (i.c.v.) at a concentration of $200 \mu \mathrm{g} / 4 \mu \mathrm{l}$ using a $10-\mu 1$ syringe stereotaxically lowered into the ventricle at the time the LC infusion needle was lowered. The syringe was filled with $4 \mu \mathrm{l}$ of propranolol followed by $0.5 \mu \mathrm{l}$ of air and then $4 \mu \mathrm{l}$ of saline. Intracerebroventricular injections consisted of $4 \mu$ l given over a $60-90 \mathrm{sec}$ interval. The injection needle remained in the ventricle until the end of the experiment.
$L C$ recording/drug infusions. The experimental preparation is depicted in Figure 1. The procedure used for LC recordings and infusions was that described previously (Adams and Foote, 1988). Briefly, a small hole $(2-3 \mathrm{~mm}$ in diameter) centered at $1.4 \mathrm{~mm}$ lateral to the midline and $4.0 \mathrm{~mm}$ caudal to the point at which the lambdoid and midline sutures intersect was drilled through the skull. A recording/infusion probe, consisting of a stainless-steel microelectrode glued parallel to a shorter piece of 26 ga hypodermic tubing, was used to locate the LC. LC neurons were tentatively identified based on previously described criteria (Valentino et al., 1983). After the LC was located, the probe was raised $2 \mathrm{~mm}$, a $33 \mathrm{ga}$ infusion needle, which extended to the depth of the electrode tip with a lateral displacement of about $300 \mu \mathrm{m}$, was inserted into the guide tube, and the probe was lowered to the depth of the LC. The infusion needle was attached to PE20 tubing via a 27 ga stainless-steel sleeve glued to the needle. The other end of the tubing was attached to a $5 \mu$ l syringe, the plunger of which was advanced using a micrometer drive. Infusions consisted of 70-135 nl of bethanechol (1 $\mathrm{ng} / \mathrm{nl} ; 5.1 \mathrm{~mm}$ ) given over a $60 \mathrm{sec}$ period. The distance separating the recording electrode and the infusion needle resulted in infusions that were always outside of the LC and thus avoided infusion-induced damage to this nucleus (Figs. 2, 3).

EEG recording. A bipolar surface-to-depth recording electrode was used to record the cortical EEG (ECoG). The electrode consisted of two adjacent varnish-insulated wires $(0.25 \mathrm{~mm}$ in diameter) with a $2 \mathrm{~mm}$ vertical tip separation. An opening was made over the left frontal cortex (A, +3.0; L, 1.5; relative to bregma, ipsilateral to LC), and the electrode was lowered until the shorter wire was $100-200 \mu \mathrm{m}$ below the cortical surface. The hole was filled with bone wax, a jeweler's screw was threaded into the skull adjacent to the electrode, and the electrode was cemented into place.

Hippocampal EEG (HEEG) recordings were made through a monopolar electrode lowered into the dorsal hippocampus (A, -4.5; L, 2.0; $\mathrm{V},-2.5$; relative to bregma, ipsilateral to $\mathrm{LC}$ ). This recording electrode was referenced to a screw electrode placed over the contralateral parietal cortex, in contact with the dura.

EEG analysis. EEG signals were amplified, filtered $(0.1-50.0 \mathrm{~Hz}$ bandpass), and recorded on a polygraph and on magnetic tape. Three $11 \mathrm{sec}$ EEG segments from each experiment, defined as "pre-infusion," "postinfusion," and "recovery," were selected for power-spectrum analysis (PSA). Each segment was digitized at a sampling frequency of $700 \mathrm{~Hz}$ and was tapered at the ends as a cosine function. The pre-infusion segment was defined as beginning $41 \mathrm{sec}$ prior to the start of the infusion. The post-infusion period began $30 \mathrm{sec}$ after the onset of the first unambiguous change in the EEG as judged by visual inspection. In all 
cases, this was within the 2 min period following initiation of the infusion. The recovery period was defined as beginning 2 min following the first reappearance of pre-infusion-like EEG activity in either channel. Each segment was subjected to fast Fourier transform and PSA. The mean absolute and mean relative power (percentage of total power) were calculated for the frequency bands $0.8-2.7 \mathrm{~Hz}, 2.7-6.8 \mathrm{~Hz}, 6.8-12.9$ $\mathrm{Hz}, 12.9-20.0 \mathrm{~Hz}, 20.0-34.7 \mathrm{~Hz}$, and $34.7-43.8 \mathrm{~Hz}$. These frequency bands were selected on the basis of visual inspection of EEG patterns as being sensitive to changes induced by sensory stimulation such as tail pinch.

Statistical analysis. Absolute power and relative power for each frequency bandwidth were analyzed by a one-way, repeated-measures ANOVA. When statistical significance was indicated $(p<0.05)$, post hoc analysis was conducted using Duncan's multiple-range test.

Histology. Following each experiment, cathodal current was passed through the LC electrode ( $10 \mu \mathrm{A} / 10 \mathrm{sec})$ to mark the recording site. The infusion needle was removed, filled with $2 \%$ Pontamine sky blue dye, and placed back into the guide tube, and $70-135 \mathrm{nl}$ of dye was infused over a $60 \mathrm{sec}$ period. The animal was deeply anesthetized and perfused with $50 \mathrm{ml}$ of a solution of $4 \%$ formaldehyde and $5 \%$ potassium ferrocyanide so that the Prussian blue reaction could be used to visualize the $\mathrm{LC}$ recording site. The brain was removed and placed in $50 \mathrm{ml}$ of the perfusion solution containing $1 \mathrm{ml}$ of glacial acetic acid. Following a minimum of $48 \mathrm{hr}$, the brain was frozen and $75 \mu \mathrm{m}$ sections were taken through the areas in which the EEG and LC recording electrodes, and when appropriate the intracerebroventricular needle, had been placed. The sections were stained with neutral red dye for subsequent examination of the $\mathrm{LC}$ recording and infusion sites and the placement of the ECoG and HEEG electrodes. An unstained section through the LC demonstrating the placement of both the recording electrode and the infusion needle for a typical experiment is shown in Figure 2. For experiments involving intracerebroventricular injections, localization of the dye in the ventricular system was noted.

Data selection. Data from a particular animal were included in the analyses when EEG electrode placements were accurate, EEG recordings were electrically adequate, and brainstem recording and infusion sites could be anatomically verified.

\section{Results}

General observations. Subjects exhibited stable EEG patterns during periods when they were not receiving sensory stimulation or LC infusions. A typical EEG record for such a period is shown in the pre-infusion portion of Figure 4. In the ECoG, slow frequencies and large amplitudes predominated. This pattern is similar to that observed during slow-wave sleep (Timo-Iaria et al., 1970). In the HEEG, mixed frequencies and amplitudes were present. These patterns were stable for up to $120 \mathrm{~min}$ once anesthetic status had stabilized. Usually, $0.5-1.0 \%$ halothane was necessary to maintain a level of anesthesia characterized by these patterns and a total lack of motor responses to noxious stimulation. This was the baseline condition under which experiments were conducted. Once data collection for a particular experiment was initiated, halothane levels were not altered. A total of 39 infusions in 28 animals were studied in these experiments.

Histological verification and effects of infusions on LC activity. Peri-LC bethanechol infusions that enhanced LC neuronal discharge activity, as verified by recordings from individual or multiple neurons, were made in 25 animals. These infusions increased LC neuronal discharge in the vicinity of the electrode three to five times baseline levels. The maximum discharge rate was attained within $1 \mathrm{~min}$ from onset of the activation and was maintained for 2-3 min. Following this, discharge rates gradually decreased over a $10-15 \mathrm{~min}$ period until reaching pre-infusion levels (see Adams and Foote, 1988). For all of these effective peri-LC bethanechol infusions, the recording site was localized to the main body of the LC, and the infusion site was generally centered within a $200-500 \mu \mathrm{m}$ radius of the nucleus

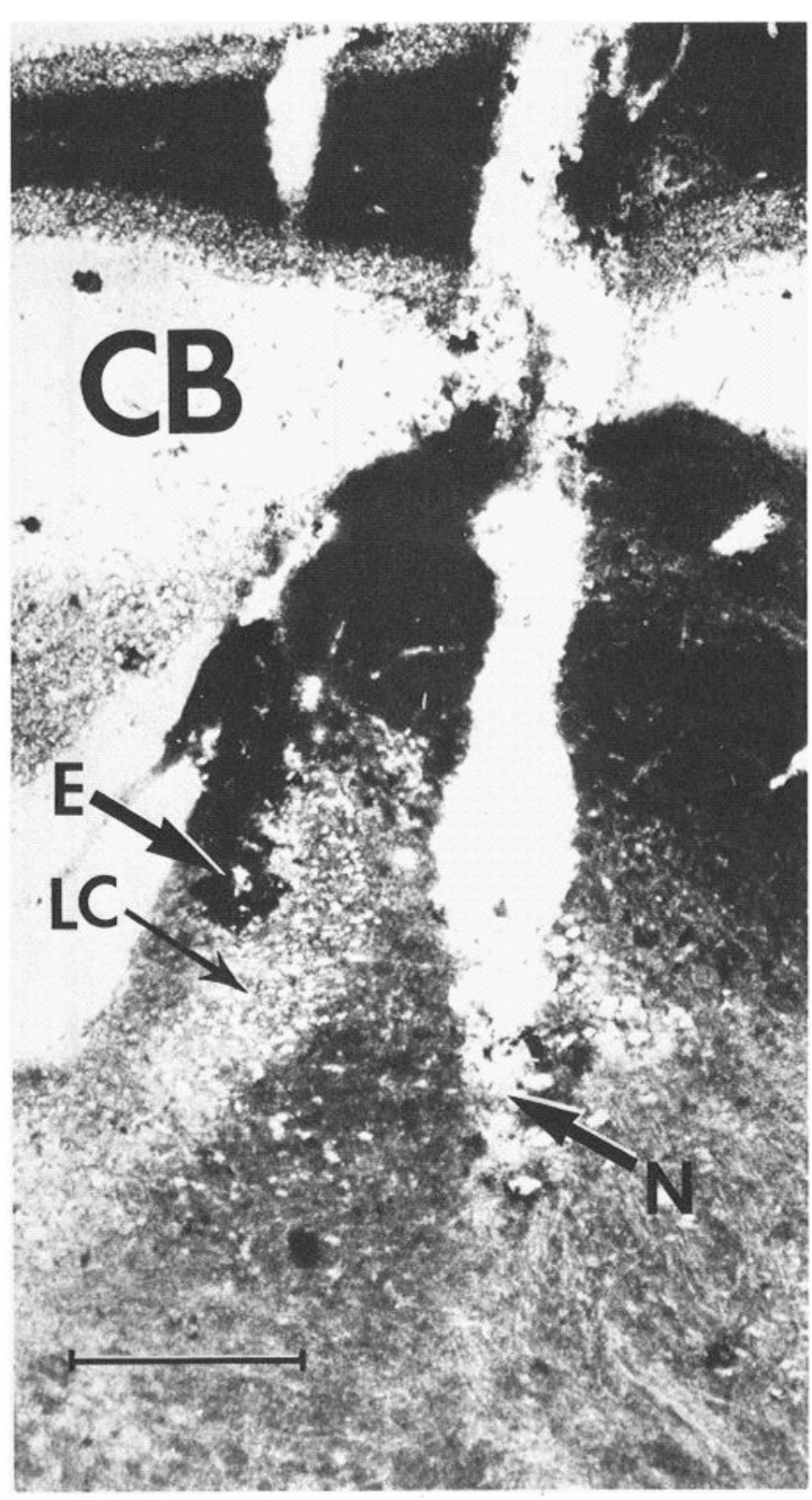

Figure 2. Photomicrograph of the LC recording and peri-LC infusion sites from a typical experiment. The LC (small arrow) is the collection of small translucent cells, the ventral border of which is even with the tip of the infusion needle $(N)$. The recording electrode site $(E)$ appears as a small dark circle on the medial edge of the LC. The dark streak extending above the recording site is blood and extends to the dorsal edge of the LC. The infusion site is the enlarged portion of the track created by the infusion needle. The large translucent cells to the right of the infusion needle tip are those of the mesencephalic nucleus of the trigeminal nerve. $C B$ indicates cerebellum. Scale bar, $250 \mu \mathrm{m}$.

(see Figs. 2, 3). In most cases, activity from one or two isolated neurons could be recorded during the baseline condition, but the infusion would activate nearby neurons sufficiently so that only multiunit activity could be recorded during the infusion and immediate post-infusion interval.

Effects of infusions on ECOG and HEEG: latency. Bethanechol infusions that activated LC neuronal discharge activity induced substantial changes in the ECoG and HEEG (see Figs. 4, 5, 7, 8). The minimum dose of bethanechol at which these effects were 
Figure 3. Schematic diagram depicting effective and ineffective bethanechol infusion sites. Level through LC was traced from a representative tissue section. Distance between the infusion sites and the LC was measured in fixed and dried tissue sections. Solid circles indicate sites at which bethanechol infusion activated the EEG. Shaded boxes indicate sites at which bethanechol infusion had no obvious EEG effects. The center of the infusion site is indicated by these symbols. Abbreviations: $M e 5$, mesencephalic nucleus of the trigeminal nerve; Mo5, motor nucleus of the trigeminal nerve; $\operatorname{Pr} 5$. principle sensory nucleus of the trigeminal nerve; $4 V$, fourth ventricle.

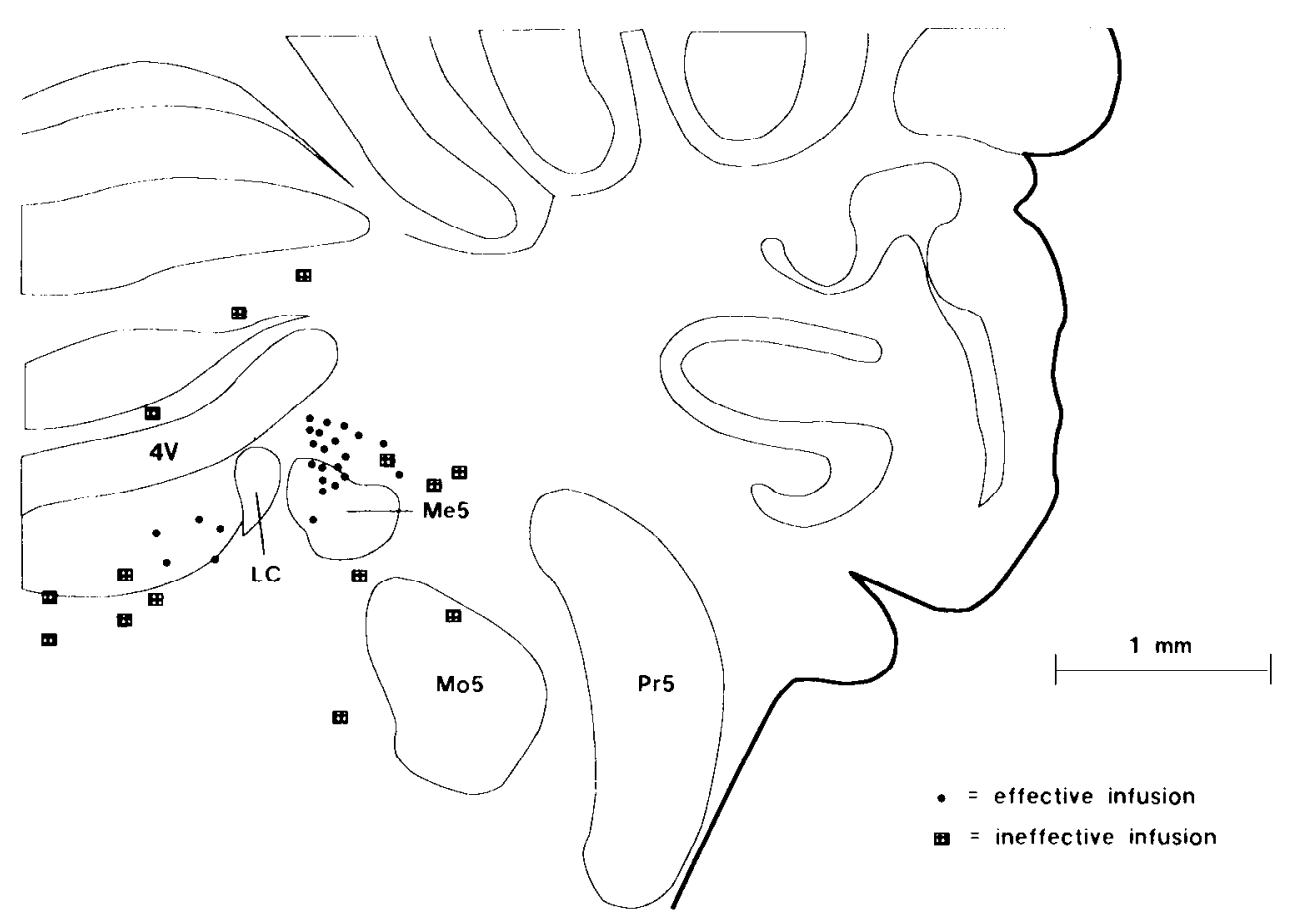

observed was $70 \mathrm{ng} / 70 \mathrm{nl}$. By visual inspection, the $\mathrm{ECoG}$ changes were composed of a dramatic decrease in average amplitude and a reduction in the prevalence of slow-wave activity. Changes in the HEEG consisted of a shift to nearly pure $\theta$-activity. In 24 of 25 animals, LC activation preceded EEG activation. For these cases, the latency between the onset of LC activation and the ECoG and HEEG changes ranged from 5 to $30 \mathrm{sec}$. ECoG and HEEG responses were observed virtually simultaneously. Infusions made either lateral (20 animals) or medial (5 animals) to $\mathrm{LC}$ resulted in similar latencies between the onset of the LC and EEG responses; latencies as short as 5 sec were observed with both medial and lateral infusions. Similar effects of bethanechol on LC and EEG activity were observed with repeated infusions separated by approximately $30 \mathrm{~min}$. In the one animal in which $E E G$ responses were observed prior to the $\mathrm{LC}$ response, histological examination revealed that this case was unique in that the recording and infusion sites were on opposite sides of the LC (medial and lateral, respectively).

Effects of infusions on ECOG and HEEG: recovery. Typically, EEG and LC activity returned gradually toward the pre-infusion state over a several-minute period beginning within the few minutes following the infusion (Figs. 4, 5). The recoveries of both the ECoG and HEEG were observed simultaneously and appeared to involve two stages. The first occurred within $5 \mathrm{~min}$ of the onset of the EEG response and consisted of a return of slow-wave activity in the ECoG and the loss of the predominance of $\theta$-like activity in the HEEG. The second phase of recovery was marked by the return of the highest frequencies in both the ECOG and HEEG. This recovery of high-frequency components was closely correlated with the return of LC discharge rates to pre-infusion levels.

Effects of infusions on ECoG and HEEG: power-spectrum analyses. The effects of peri-LC infusions on ECoG and HEEG power spectra were statistically analyzed for the first 11 animals. Because of variability in EEG recording electrode placement, it was not always possible to obtain both ECoG and HEEG recordings from all animals. The PSA results were consistent with the qualitative observations described above (Fig. 5, Table 1).
In the ECoG, peri-LC infusions significantly decreased the mean absolute power of all frequency bands. The magnitude of this decrease $(p<0.01)$ ranged from $64 \%$ in the $0.8-2.7 \mathrm{~Hz}$ band to $30 \%$ in the $34.7-43.8 \mathrm{~Hz}$ band. Relative power was significantly decreased $(p<0.01)$ in the $0.8-2.7 \mathrm{~Hz}$ frequency band and significantly increased $(p<0.01)$ in the $20.0-34.7 \mathrm{~Hz}$ and $34.7-43.8 \mathrm{~Hz}$ bands. Two minutes following the return of largeamplitude, slow-frequency components of the ECoG, the majority of these power spectrum effects had disappeared. The exception to this was the persistence of a significant decrease ( $p$ $<0.05)$ in the mean absolute power of the highest $(34.7-43.8$ $\mathrm{Hz}$ ) frequency band.

In the HEEG, bethanechol infusions significantly decreased $(p<0.01)$ the absolute power of all frequency bands except that of the $2.7-6.8 \mathrm{~Hz}(\theta)$ band. Correspondingly, the relative power of the $2.7-6.8 \mathrm{~Hz}$ frequency band was increased $(p<0.01)$. The relative power of the $0.8-2.7 \mathrm{~Hz}$ frequency band was significantly decreased $(p<0.01)$.

By visual inspection and PSA, these bethanechol-induced EEG effects were similar to those observed in this preparation following noxious stimulation, such as tail pinch or paw pinch (Fig. 6).

Effects of infusions on ECoG and HEEG: control infusions. In a further set of experiments, a number of infusions were made at varying distances $(500-1200 \mu \mathrm{m})$ outside the immediate vicinity of the LC that were without effect on either ECoG or HEEG activity (Fig. 3). The majority (11 of 14) of these infusions were made in animals in which a peri-LC infusion was observed to increase LC neuronal discharge activity and induce the EEG responses described above. The remaining three infusions were made inadvertently outside the immediate region of the LC. All of these infusions were made in animals in which tail pinch activated both ECoG and HEEG. The location and distances from the LC (measuring the distance between the center of the infusion and the point along the LC border closest to the infusion) of these ineffective sites included (1) the cerebellum just above the fourth ventricle (three infusion sites, 500,700, and $900 \mu \mathrm{m}$ dorsal to $\mathrm{LC}$ ); (2) directly lateral to the $\mathrm{LC}$ (two infusion 

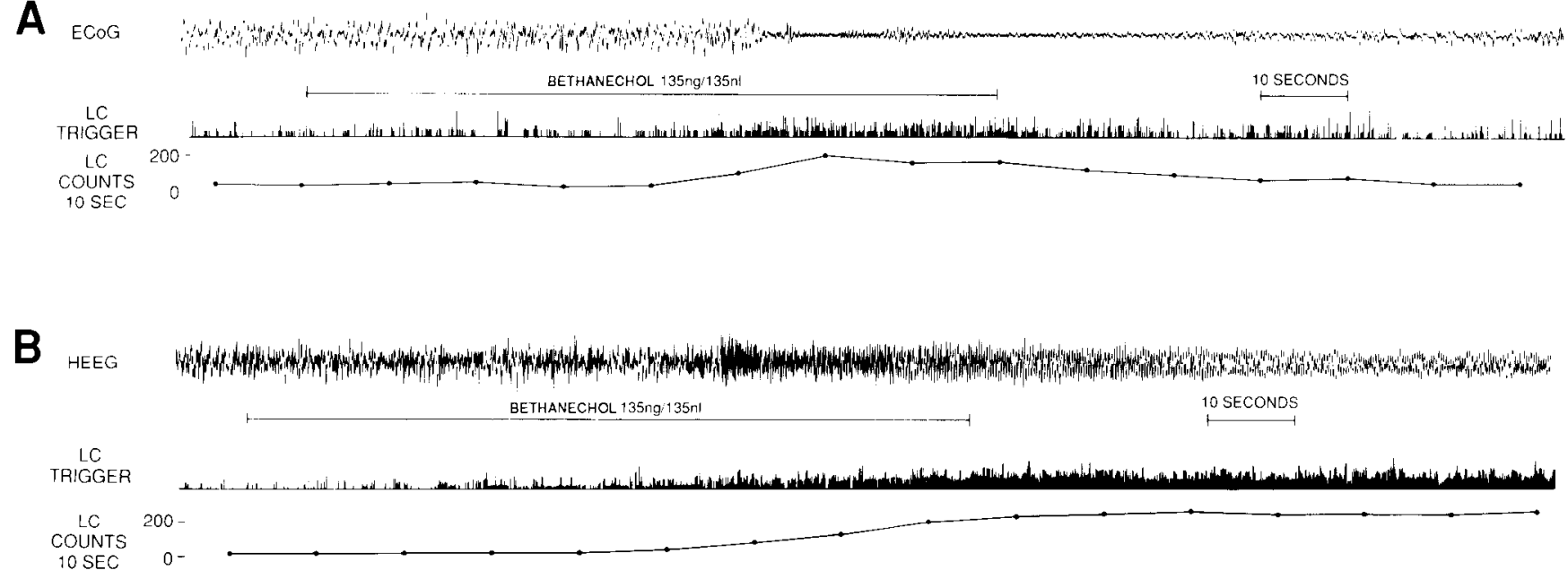

Figure 4. Relationship of LC activity to ECoG $(A)$ and HEEG $(B)$ before, during, and after peri-LC bethanechol infusions. $A$ and $B$ represent data from separate experiments. In each experiment, bethanechol-induced changes in EEG activity were observed simultaneously in both the ECoG and HEEG recordings. Bethanechol was infused at a constant rate throughout the interval indicated. EEG activity is shown in the top trace of each panel, the raw trigger output from LC activity in the middle trace, and the integrated trigger output ( 10 sec intervals) in the bottom trace. In $A$, LC activity is seen to increase during the latter part of the infusion, and several seconds later, reduced amplitude and increased frequency become evident in the ECoG trace. As LC activity begins to decrease following the infusion, ECoG amplitude begins to increase and its frequency decreases. In $B$, enhanced LC activity becomes evident in the latter part of the infusion period, and several seconds later $\theta$-rhythm begins to dominate the HEEG trace. For the remainder of the trace, LC activity remains elevated and $\theta$-rhythm predominates.

sites, 700 and $800 \mu \mathrm{m})$; (3) ventrolateral to the LC(three infusion sites, 500,1000 , and $1200 \mu \mathrm{m}$ ); and (4) ventromedial to the LC (five infusion sites, $500,650,700,900$, and $1000 \mu \mathrm{m}$ from LC). In the sites ventrolateral to the LC, bethanechol infusions increased the discharge rates of nearby neurons. Finally, a periLC saline infusion ( $300 \mu \mathrm{m}$ from LC) had no effect on either LC activity or measures of EEG in an animal in which both of these measures subsequently responded to bethanechol infusion (data not shown).

Effects of infusions on ECoG and HEEG: antagonism by clonidine and propranolol. To test the dependence of bethanecholinduced EEG activation on NE release, the effects of the $\alpha_{2}$ agonist clonidine, known to suppress $L C$ firing and NE release (Svensson et al., 1975; Warsh et al., 1981), and the $\beta$-adrenergic antagonist propranolol on the EEG response to $\mathrm{LC}$ activation were examined.
To determine the effects of clonidine $(n=5)$, the sequence of treatments was as follows: (1) bethanechol infusion without a preceding intravenous injection, (2) bethanechol infusion $2 \mathrm{~min}$ after intravenous saline, (3) bethanechol infusion 2 min after intravenous clonidine $(50 \mu \mathrm{g} / \mathrm{kg})$. All intravenous injections were administered $15 \mathrm{~min}$ after the return of EEG activity to baseline following the previous infusion. In all five animals, peri-LC bethanechol, either alone or following intravenous saline, activated the ECoG and HEEG in a manner similar to that described above. Clonidine severely inhibited basal LC neuronal discharge activity. However, it did not completely prevent an activation of LC neurons by bethanechol. Clonidine increased basal slow-wave activity and blocked $(n=4)$ or severely attenuated ( $n=1)$ bethanechol-induced changes in both ECoG and HEEG activity (data not shown). This dose of clonidine also appeared to increase the level of anesthesia of the animal as

Table 1. Mean absolute and relative power of post-infusion and recovery segments of ECoG and HEEG (expressed as percentage of pre-infusion means)

\begin{tabular}{|c|c|c|c|c|}
\hline \multirow[t]{2}{*}{ Frequency $(\mathrm{Hz})$} & \multicolumn{2}{|c|}{ Absolute power } & \multicolumn{2}{|c|}{ Relative power } \\
\hline & Post & Recovery & Post & Recovery \\
\hline \multicolumn{5}{|l|}{$\overline{\text { ECoG }}$} \\
\hline $0.8-2.7$ & $36 \pm 5^{* *}$ & $109 \pm 8$ & $72 \pm 6^{* *}$ & $110 \pm 9$ \\
\hline $2.7-6.8$ & $59 \pm 10^{* *}$ & $107 \pm 7$ & $111 \pm 8$ & $106 \pm 5$ \\
\hline $6.8-12.9$ & $47 \pm 6^{* *}$ & $90 \pm 10$ & $94 \pm 5$ & $88 \pm 7$ \\
\hline $12.9-20.0$ & $50 \pm 7^{* *}$ & $93 \pm 14$ & $102 \pm 8$ & $90 \pm 11$ \\
\hline $20.0-34.7$ & $63 \pm 9^{* *}$ & $90 \pm 14$ & $132 \pm 14^{* *}$ & $89 \pm 11$ \\
\hline $34.7-43.8$ & $70 \pm 11^{* *}$ & $89 \pm 10^{*}$ & $141 \pm 17^{* *}$ & $85 \pm 12$ \\
\hline \multicolumn{5}{|l|}{ HEEG } \\
\hline $0.8-2.7$ & $49 \pm 13^{* *}$ & $86 \pm 16$ & $74 \pm 8^{* *}$ & $106 \pm 6$ \\
\hline $2.7-6.8$ & $86 \pm 8$ & $80 \pm 14$ & $132 \pm 7^{* *}$ & $96 \pm 5$ \\
\hline $6.8-12.9$ & $65 \pm 7^{* *}$ & $90 \pm 14$ & $90 \pm 4$ & $103 \pm 10$ \\
\hline $12.9-20.0$ & $67 \pm 6^{* *}$ & $95 \pm 16$ & $100 \pm 4$ & $109 \pm 4$ \\
\hline $20.0-34.7$ & $61 \pm 5^{* *}$ & $84 \pm 17$ & $92 \pm 3$ & $88 \pm 5$ \\
\hline $34.7-43.8$ & $66 \pm 10^{* *}$ & $102 \pm 21$ & $100 \pm 5$ & $143 \pm 43$ \\
\hline
\end{tabular}

Absolute and relative power are expressed as percentages of pre-infusion means ( \pm SEM) for ECoG and HEEG for the specified frequency bands $(n=11)$.

${ }^{*} p<0.05 ;{ }^{* *} p<0.01$; significantly different from pre-infusion mean. 
PRE-INFUSION

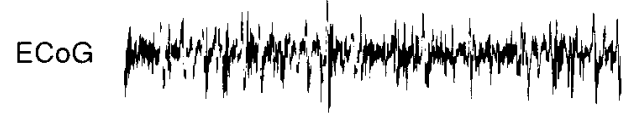

HEEG
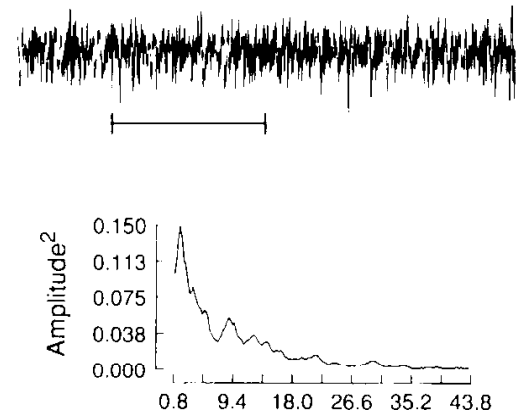

$\mathrm{Hz}$

HEEG

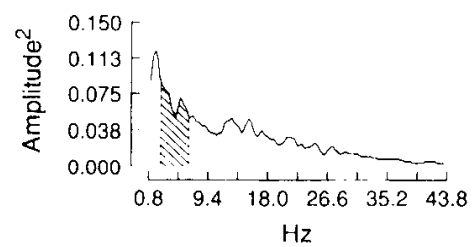

POST-INFUSION
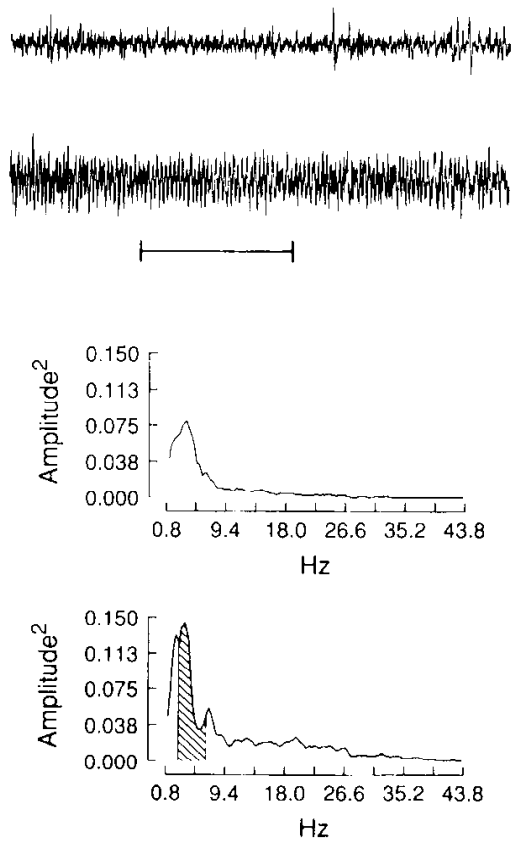

RECOVERY
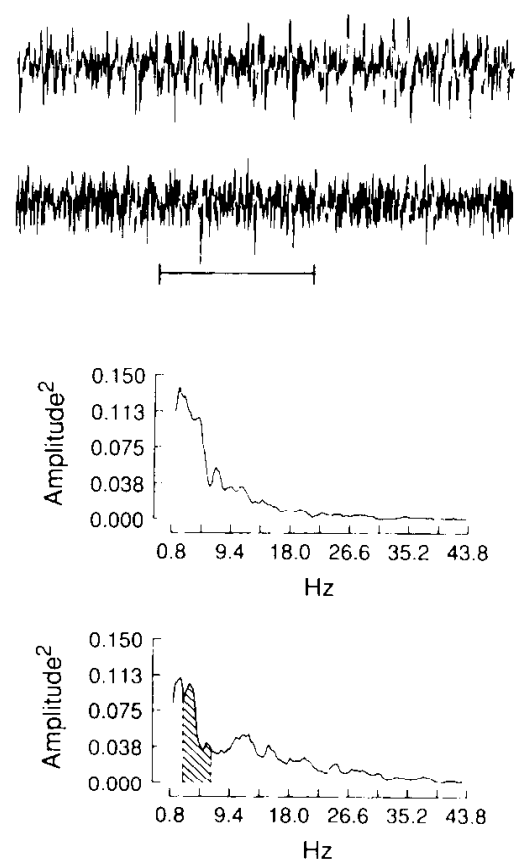

Figure 5. Raw EEG data (top traces) and power-spectrum analyses (bottom panels) from the pre-infusion, post-infusion, and recovery periods of a typical experiment. Bars indicate the exact $11 \mathrm{sec}$ interval utilized for each power-spectrum analysis. There is an 80 sec gap between the preand post-infusion traces, and a $5 \mathrm{~min}, 20 \mathrm{sec}$ gap between the post-infusion and recovery traces. The most striking post-infusion changes are the loss of activity at approximately $1 \mathrm{~Hz}$ in both traces and the emergence of dominant $\theta$-activity in the HEEG trace and power spectrum. Shading indicates the frequency band corresponding to $\theta(2.7-6.8 \mathrm{~Hz})$ in the HEEG power spectra.

indicated by the blockade of the tail pinch-induced activation of both the ECoG and HEEG, an effect that persisted for approximately $40 \mathrm{~min}$.

To test the effect of $\beta$-adrenergic receptor blockade, the $\beta$-antagonist propranolol ( $200 \mu \mathrm{g}$, i.c.v. $)$ was administered prior to bethanechol infusion $(n=6)$. The sequence of treatments was as follows: (1) bethanechol infusion without a preceding intracerebroventricular injection, (2) bethanechol infusion 15 min after intracerebroventricular saline, (3) bethanechol infusion $15 \mathrm{~min}$ after intracerebroventricular propranolol, (4) in some animals, bethanechol infusion $60 \mathrm{~min}$ after intracerebroventricular propranolol. Intracerebroventricular injections were performed 15 min after the EEG had recovered from the preceding carbachol infusion. In all six animals, bethanechol, alone or following intracerebroventricular saline, affected LC and EEG activity as described above. Propranolol had no effect on basal or bethanechol-induced changes in LC activity. In five of six animals, propranolol increased slow-wave activity in both the HEEG and ECoG. In three of these animals, this effect persisted the entire $15 \mathrm{~min}$ prior to bethanechol infusion. Propranolol blocked $(n=4)$ or severely attenuated $(n=2)$ the bethanecholinduced activation of both the ECOG and HEEG. In one of the four animals, the HEEG electrode placement was immediately ventral to the hippocampus. The effect of bethanechol as recorded at this electrode was primarily an increase in high-frequency activity, and this was completely blocked by propranolol. The effectiveness of propranolol was noticeably diminished $60 \mathrm{~min}$ following intracerebroventricular administration. Propranolol did not affect or only slightly diminished tail pinchinduced activation of either the ECOG or HEEG. Data from thrce animals with good HEEG rccordings arc shown in Figures 7 and 8 . Similar effects were observed with intravenous pro- pranolol administration $(2-5 \mathrm{mg} / \mathrm{kg})$. With this route of administration, however, a transient activation of EEG activity was observed immediately following injection, likely due to cardiovascular effects of peripherally administered propranolol.

\section{Discussion}

Summary of results. Peri-LC infusions increased LC neuronal discharge rates and resulted in pronounced changes in the $\mathrm{ECoG}$ and HEEG within 5-30 sec following the onset of LC activation. ECoG changes were characterized by a reduction of absolute power at all frequency bands examined, decreased relative power in the lowest frequencies, and an increase in relative power at the highest frequencies. In the hippocampus, LC activation was followed by the appearance of nearly pure $\theta$-activity (2.7$6.8 \mathrm{~Hz})$. The recovery of both ECoG and HEEG involved two general stages. The first was characterized by a recovery of lowfrequency power within 2-5 min, while the second was marked by the return of the higher frequencies. This second stage normally occurred $10-15 \mathrm{~min}$ after the infusion and was closely correlated with the completion of the recovery of LC discharge rates to baseline levels. These effects were not observed when the infusions were made outside the immediate region of the LC and were blocked by intravenous clonidinc or intracerebroventricular propranolol.

Methodological considerations. The present and previous observations (Adams and Foote, 1988) indicate that exact placement of the infusion needle in a pericoerulear position is critical for producing reliable effects on LC neuronal discharge activity. Differences of $200 \mu \mathrm{m}$ in any dimension in the placement of this ncedlc profoundly alter the effects of the infusion. Accurate placement of the infusion diminishes the volume and concen- 
ECoG

\section{PRE- $\mathrm{PINCH}$}
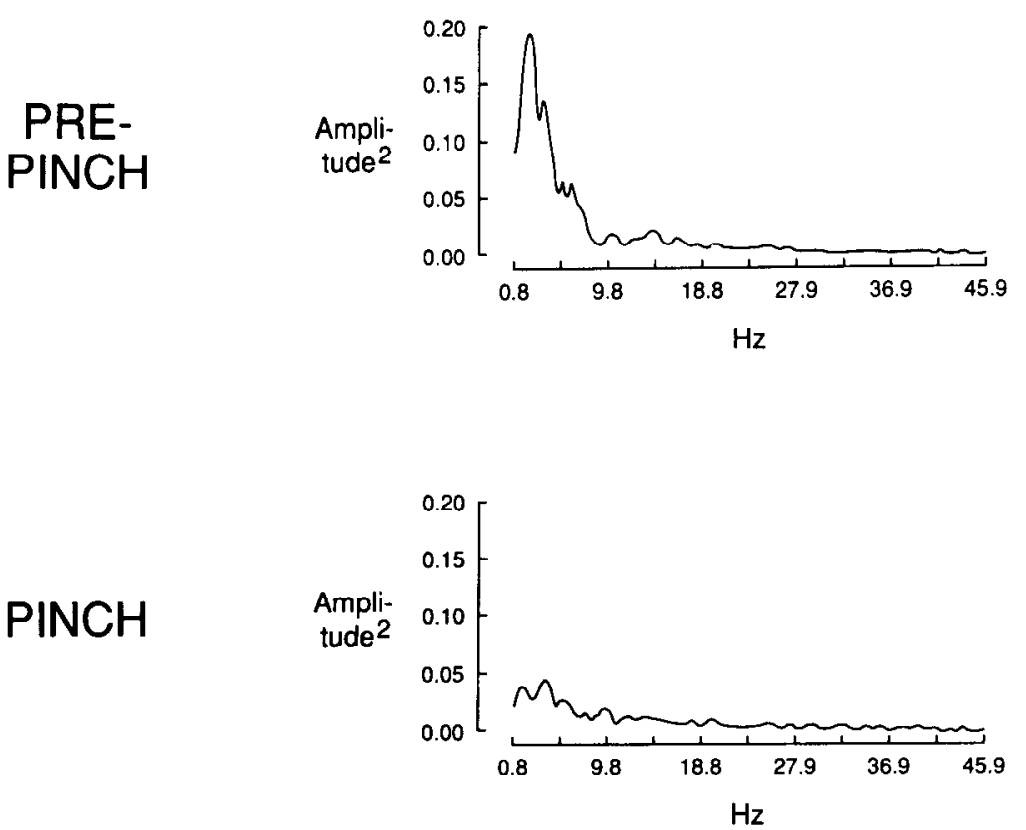

\section{HEEG}
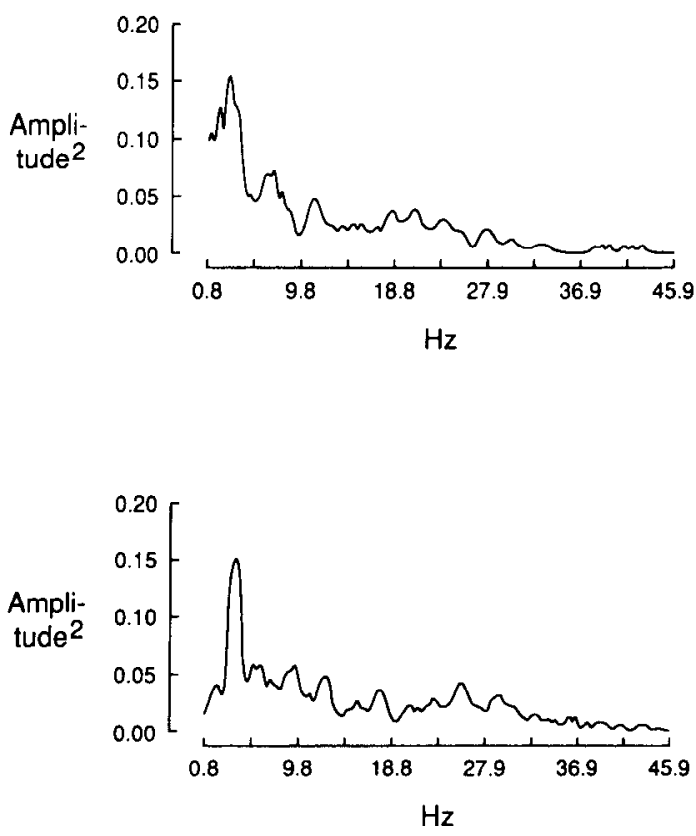

Figure 6. Power spectra illustrating the effect of foot pinch on ECuG and HEEG activity. Pre-pinch data illustrate typical baseline activity. The pinch spectra reflect the decreased slow-wave activity and proportionately increased high-frequency activity in the ECoG, and the increased $\theta$-activity in the HEEG.

tration of drug needed to obtain a particular level of effect. These and other observations (Adams and Foote, 1988) indicate that the effective size of the infusion site is no larger than 400-500 $\mu \mathrm{m}$ in radius. This greatly increases the power of the inference that the site of action is within a short distance of the tip of the infusion needle. Similar restricted effects of small, local infusions on physiological and behavioral responses have been reported by others (e.g., S. P. Zhang et al., 1990; X. Zhang et al., 1990).
The above observations are in apparent conflict with the observed spread of small infusions $(100 \mathrm{nl})$ of radiolabeled carbachol over an area with a radius of approximately $1 \mathrm{~mm}$ (Gnadt and Pegram, 1986). However, in this study, the exposure time ( 3 weeks) was adjusted to permit a sensitivity capable of detecting radioactivity at a concentration of $1 / 10,000$ that of the infusate. The dose of bethanechol used in the present studies is such that dilution of this dose by a factor of 10 would eliminate any physiological effects on the LC (Adams and Foote, 1988).
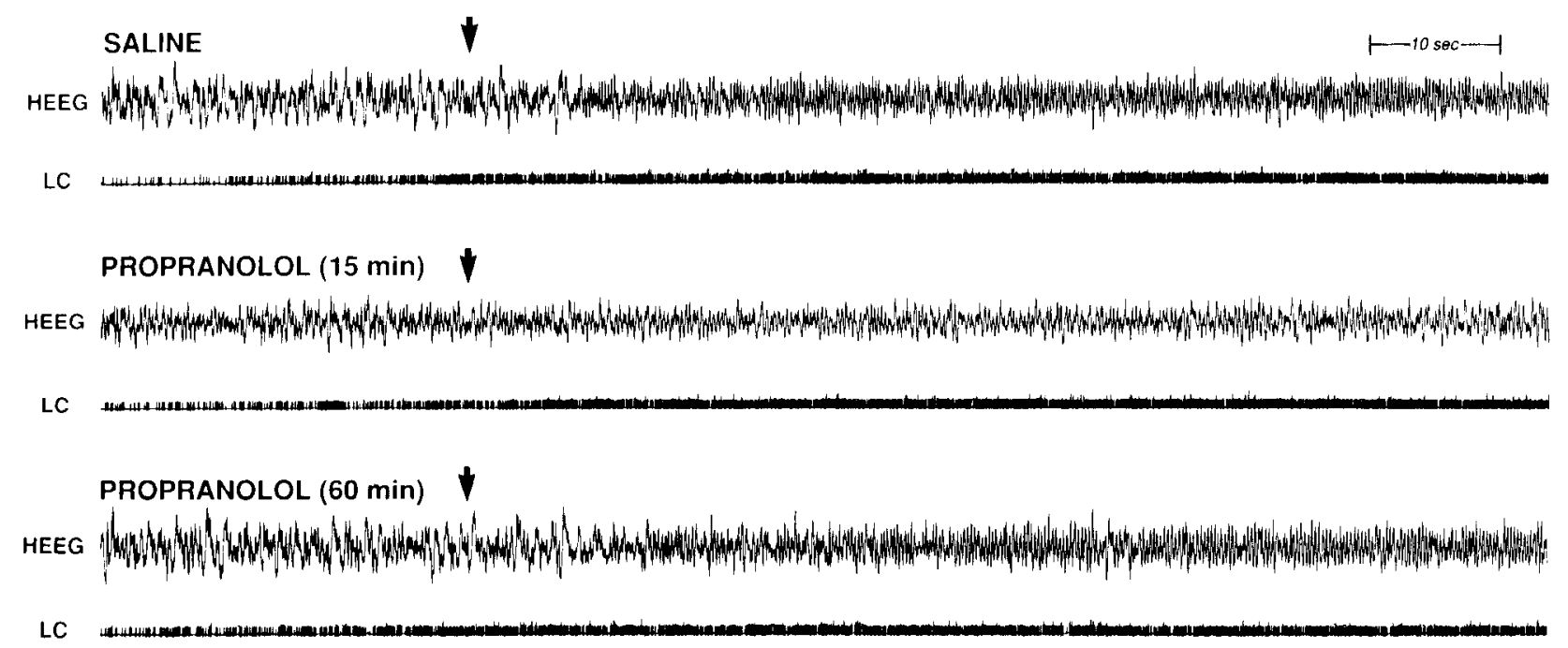

Figure 7. Effect of intracerebroventricular propranolol $(200 \mu \mathrm{g})$ on the peri-LC bethanechol-induced activation of HEEG. Bethanechol (100 $\mathrm{nl})$ was infused $15 \mathrm{~min}$ after intracerebroventricular saline, $15 \mathrm{~min}$ after intracerebroventricular propranolol, and 60 min after intracerebroventricular propranolol in the same animal. LC multiunit activity is shown in the trace labeled $L C$. The arrows indicate the end of the bethanechol infusion. Propranolol did not affect the carbachol-induced increase in LC activity. HEEG activation, as indicated by the appearance of $\theta$-activity, is greatly diminished $15 \mathrm{~min}$ after propranolol administration. This reduction is less pronounced 60 min after propranolol administration. 
A

SAL

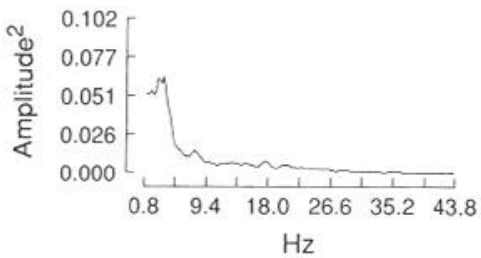

PRO

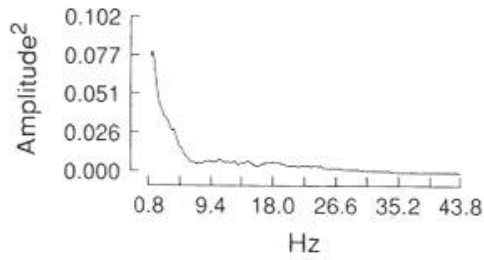

B

SAL
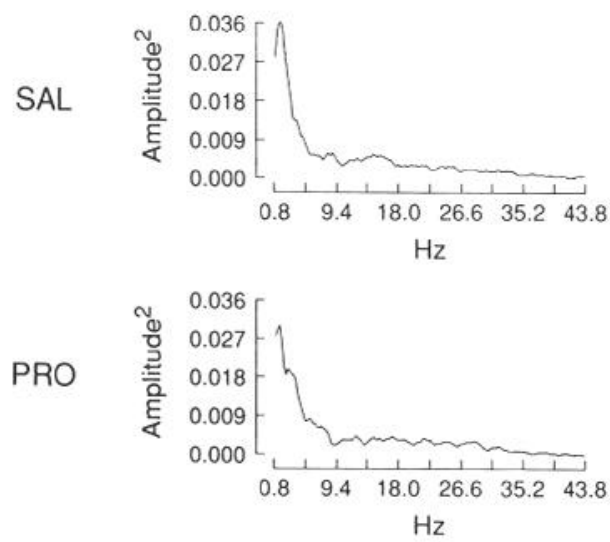

POST-INFUSION (30 sec)
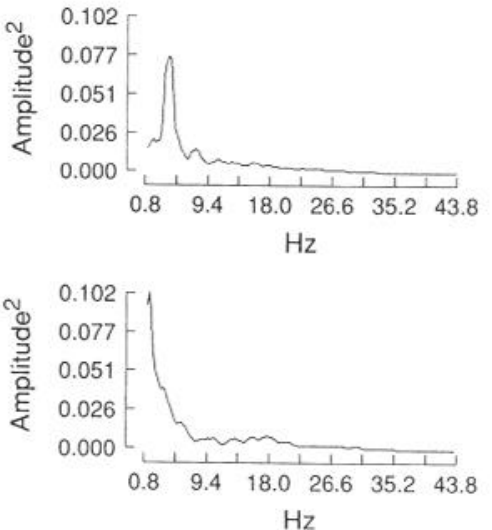

POST-INFUSION (30 sec)
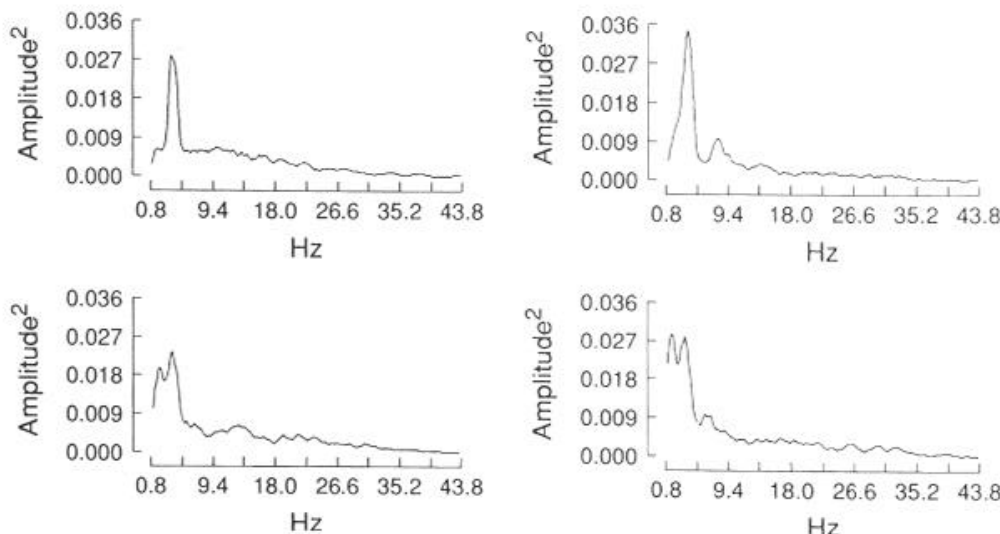

Figure 8. Effect of propranolol on peri-LC bethanechol-induced activation of HEEG in two animals $(A$ and $B)$. Bethanechol was infused 15 min following an intracerebroventricular injection of saline $(S A L)$ or $200 \mu \mathrm{g}$ of propranolol $(P R O)$. PSA was performed on 11 sec HEEG segments starting $41 \mathrm{sec}$ prior to the start of the bethanechol infusion (pre-infusion), and either $30 \mathrm{sec}$ [post-infusion ( $30 \mathrm{sec}$ )] or $2 \mathrm{~min}$ [post-infusion ( 2 min)] after the first appearance of a change in EEG activity. When there was no obvious HEEG response (propranolol condition, $A$ ), an HEEG segment was used that began the same number of seconds following the start of LC activation as occurred in the saline condition. In the presence of saline, bethanechol decreased slow-wave and increased $\theta$-activity. This effect was not diminished 2 min after the onset of the HEEG activation. Propranolol blocked this activation in animal $A$ and severely attenuated it in animal $B$.

Other documented physiological and behavioral effects of carbachol do not display a greater sensitivity than that we observe on LC activation (Gnadt and Pegram, 1986; Baghdoyan et al., 1987, 1989; Sakai et al., 1990). Therefore, it is extremely unlikely that the spread of carbachol over a distance of $1 \mathrm{~mm}$ accurately reflects the range over which small infusions of carbachol elicit physiological effects.

Our experience has consistently been that LC activation is not observed unless the beveled side of the infusion needle is pointing directly toward the LC, even when in close proximity to the recording electrode $(200-400 \mu \mathrm{m})$. This indicates that in the present experiments, diffusion was extremely limited (less than $400 \mu \mathrm{m}$ ) in the direction directly behind and to the sides of the infusion needle. Together, our observations suggest that bethanechol infusions alter neuronal discharge activity within a highly restricted zone around the infusion needle. Furthermore, they highlight the need for electrophysiological verification of the effective size and duration of action of local infusions and indicate that the spread of a physical marker (dye, radioactivity) is not sufficient in this regard.
Site of action. The observation that LC activation precedes forebrain EEG changes and does so with relatively short latencies strongly implies that LC activation is the crucial mediating event in producing these infusion-induced EEG effects. In the only case where LC activation followed the EEG response, the LC recording electrode and infusion needle were positioned such that the drug diffused across the width of the LC to activate neurons in the vicinity of the recording electrode. Thus, in this case a majority of LC neurons were presumably activated prior to the activation recorded by the electrode. Furthermore, neither LC activation nor changes in the EEG were ever observed in the absence of the other. Infusions made at distances greater than 500-600 $\mu \mathrm{m}$ from the LC were without effect on either the ECoG or HEEG, indicating that bethanechol is not acting at sites distant from the LC.

Although the present method and results cannot entirely preclude the possibility that another structure within a few hundred microns of the LC is the primary site of action for the observed EEG effects, the following observations argue against this possibility. First, the ability of the $\alpha_{2}$-agonist clonidine and the 
$\beta$-antagonist propranolol to block or severely attenuate the bethanechol-induced EEG activation indicates the dependence of this activation on NE release. Clonidine appeared to increase the level of anesthesia in our preparation, an action consistent with previously described effects of this drug (Kaukinen and Pyykko, 1979; Bloor and Flacke, 1982). Such an effect could result from an action not related to the inhibition of NE release (stimulation of postsynaptic $\alpha_{2}$-receptors) or through the modulation of an alternate neural pathway. Therefore, it is possible that the blockade of the bethanechol-induced EEG activation resulted from the enhanced level of anesthesia and not through a mechanism related to the activity status of the LC-noradrenergic system. However, such an argument cannot be made for the ability of propanolol to block the bethanechol-induced EEG activation. Propanolol did not appear to affect the level of anesthesia as judged by EEG responsivity to sensory stimulation (tail pinch). Second, similarly short latencies (within $5 \mathrm{sec}$ ) between activation of the LC and EEG were observed whether the infusions were placed laterally or medially to the LC. The short time between LC and EEG activation, with LC activation preceding EEG activation regardless of position relative to the $\mathrm{LC}$, reduces the plausibility of an alternative site of action either directly lateral or medial to the LC. For example, if the critical site were medial to the LC, then medially placed infusions should have activated the EEG prior to LC activation, or at least with a shorter latency between LC activation and EEG activation than laterally placed infusions. Furthermore, such a site of action would not be consistent with the pattern of the effective and ineffective infusion sites we observed (Fig. 3).

Other brainstem areas implicated in the regulation of EEG activity include the dorsal raphe, the peribrachial region of the peripeduncular tegmental area, and the lateral dorsal tegmental nucleus (LDT). Of these, only the LDT is possibly sufficiently close to the LC to have been affected by the bethanechol infusions. However, the main body of the LDT is a minimum of $600-800 \mu \mathrm{m}$ anterior to that of the LC where the majority of our bethanechol infusions were made. Thus, for the reasons stated above, it is extremely unlikely that bethanechol acted at the LDT to produce EEG activation in these experiments. Furthermore, carbachol (a cholinergic agonist) has a predominantly inhibitory effect on LTD neurons in vitro and in vivo (Leonard and Llinas, 1988; El Mansari et al., 1990), an effect that would be predicted to inhibit EEG activation (Steriade et al., 1990). Finally, such an action would not be consistent with the antagonism of the bethanechol-induced EEG activation by clonidine and propranolol.

Taken together, the above observations indicate the dependence of the bethanechol-induced EEG activation on LC activation under these experimental conditions. The present results are consistent with the observation that noradrenergic $\alpha_{1}$-agonists increased EEG measures of wakefulness in rats (Pellejero et al., 1984) and cats (Hilakivi, 1983). Similar results have been observed following administration of the $\alpha_{2}$-antagonist yohimbine at a dose that increases NE release (Pellejero et al., 1984). The mixed results observed following administration of the $\alpha_{1}$ antagonist prazosin (Makela and Hilakivi, 1986; Kleinlogel, 1989) could be explained by the action of parallel neural systems unaffected by this treatment that also activate EEG.

The present results are especially interesting because they indicate that LC activity levels are not only correlated with but can be causally related to mcasures of forcbrain activation. Specifically, LC activation may be sufficient, although possibly not necessary, for forebrain activation. This hypothesis is compatible with the idea that there are other ascending activating systems that are also sufficient but not necessary for forebrain arousal (Vanderwolf and Robinson, 1981; Buzsaki et al., 1988; Steriade and McCarley, 1990). The apparently redundant and/ or compensatory actions of other ascending activating systems could explain why LC-noradrenergic lesions that are followed by a recovery period have often been ineffective in altering patterns of EEG activity (see Vanderwolf and Robinson, 1981). Also, it is possible that in the anesthetized preparation used in the present studies, the activating effects of these other systems are largely blocked or diminished, permitting the effects of experimentally induced LC activation to become fully expressed.

Although it is well established that there are monosynaptic projections from the LC to neocortex and hippocampus (reviewed in Foote et al., 1983), the present studies did not address whether these projections mediate the EEG effects observed following $\mathrm{LC}$ activation. Alternatively, LC noradrenergic input to other regions known to modulate ECoG and HEEG, such as the nucleus reticularis and relay nuclei of the thalamus, or septal and brainstem cholinergic nuclei, could also explain the observed results (Buzsaki et al., 1983; Vanderwolf, 1988; Pape and McCormick, 1989; Steriade et al., 1990). Many different physiological effects of $\beta$-receptor stimulation have been observed in these regions (see McCormick and Pape, 1990; Nicoll et al., 1990). Our observations do not address which of these $\beta$-receptor-mediated effects might be responsible for the observed LC stimulation-induced activation of forebrain EEG.

The ability of bethancchol to activate LC discharge rates in vivo is consistent with the observations of in vitro studies on cholinergic modulation of LC neuronal activity (Egan and North, 1985). The extremely high AChE content of the LC suggests that it receives a cholinergic innervation, although it has been difficult to demonstrate cholinergic axons in the rat LC (Ruggiero et al., 1990; but see Shipley et al., 1990). The source of any possible cholinergic innervation is presently unknown. Given the evidence indicating a cholinergic modulation of EEG activity (Vanderwolf, 1988; Steriade et al., 1990), it is possible that one pathway through which cholinergic systems modulate EEG activity involves the activation of LC-noradrenergic neurons and that bethanechol infusions crudely mimic the activity of such input.

Significance of the anesthetized preparation. In halothaneanesthetized rats, cortical and hippocampal EEG typically exhibit activity similar to that of slow-wave slccp. However, periods of EEG activity much like those observed during waking are sometimes evident spontaneously and are reliably observed following delivery of a noxious stimulus, such as a tail pinch, even in the absence of any overt response to such stimulation. This anesthetized preparation offered distinct advantages for the present study. The EEG status of the unstimulated, anesthetized animal is quite stable and offers a reliable baseline against which to assess the effect of treatments. Also, the recording of LC neuronal activity is achieved much more easily than in the unanesthetized preparation and similarly displays stable discharge rates, making reliable, reversible activation feasible. It is possible that the processes underlying LC-induced forebrain activation in the present study reflect mechanisms that also influence EEG status in the unanesthetized rat. The EEG changes observed after LC infusion mimic those induced by noxious stimulation in the anesthetized rat and those that accompany certain episodes of arousal in unanesthetized rats. 
In any case, the degree of involvement of the LC in regulating EEG activation and behavioral arousal in the unanesthetized animal remains to be determined.

Sedative effects of $\alpha_{2}$-agonists. Also consistent with the current observations are the sedative effects of acute systemic, intracerebroventricular, or intra-brainstem administration of drugs that interfere with central NE neurotransmission. For example, the sedative effects of certain $\alpha_{2}$-adrenergic agonists such as clonidine are well known (Gatti et al., 1988; Waterman et al., 1988). Such agents are now commonly used as adjuncts to surgical anesthesia since they reduce the effective anesthetic dose (Kaukinen and Pyykko, 1979; Bloor and Flacke, 1982).

The observation that enhanced LC activity produces forebrain activation lends indirect support to the hypothesis that part of the sedative effects of $\alpha_{2}$-agonists may be mediated by their inhibition of LC neurons. The most relevant previous observations are those of De Sarro et al. (1987, 1988, 1989), who found that infusions of clonidine into the region of the LC in unanesthetized rats produced sedation while infusions of yohimbine (an $\alpha_{2}$-antagonist) produced ECoG activation. Although provocative, these studies have technical limitations, such as the large volumes and high delivery rates of the infusions and the lack of electrophysiological verification of the placement of the probe, that make interpretation of the results difficult.

Is the activation observed like that of REM sleep? An alternative interpretation of the present observations is suggested by previous findings that carbachol infusions at certain brainstem sites produce REM sleep-like states that are also characterized by EEG signs of intense arousal (Hobson et al., 1986; Baghdoyan et al., 1987, 1989). These states often include the striking muscle atonia of REM sleep. It is possible that our peri-LC infusions elicited an REM sleep-like state by acting either on the LC or on some other site. Some observations that argue against this interpretation are (1) the effective sites for eliciting REM sleeplike states are not near LC (except see Vanni-Mercier et al., 1989); (2) the effects of the present peri-LC infusions are only evident when infusion sites are within about $500 \mu \mathrm{m}$ of LC; and (3) the REM sleep-like states produced by carbachol infusions usually require much larger infusions and have a longer latency to onset and duration than the effects we observed. Furthermore, the placements of many of our ineffective infusions were close to a region of the anterodorsal pontine tegmentum previously described as being particularly effective for carbachol-induced desynchronized sleep (Baghdoyan et al., 1987). Finally, LC neurons are essentially silent during physiological REM sleep (Hobson et al., 1975; Foote et al., 1980; Aston-Jones and Bloom, 1981). Thus, the state induced in the present studies would be very unlike physiological REM sleep, since LC neurons were highly activated.

Possible relevance to behavior. The EEG changes observed after LC infusion mimic those induced by noxious stimulation in anesthetized rats and those that accompany certain episodes of arousal in unanesthetized rats. These observations suggest that the LC-noradrenergic system might be a regulator of forebrain activation in behaving animals. Vanderwolf and colleagues have suggested that behavior can be divided into two general categories (see Vanderwolf and Robinson, 1981). The first, termed type I, can he referred to as voluntary or purposeful and includes behaviors such as walking, running, and isolated movements of the head. These behaviors are always associated with $\theta$-activity in the hippocampus. Type II behaviors include licking, chewing, and grooming and are not associated with hippocampal $\theta$-activity. This is of interest in that this general classification of behaviors is analogously correlated with LC activity (Aston-Jones and Bloom, 1981). During automatic-type behaviors such as grooming and eating the LC is relatively inactive. However, when the animal moves its head to attend to the environment or engages in other behaviors directed toward the environment, the discharge rate of LC neurons increases. Thus, it is possible that the classification of type I and type II behaviors in terms of hippocampal $\theta$ might, in part, result from a relationship between LC activity, hippocampal $\theta$, and type I behaviors.

\section{References}

Adams LM, Foote SL (1988) Effects of locally infused pharmacological agents on spontaneous and sensory-evoked activity of locus coeruleus neurons. Brain Res Bull 21:395-400.

Aston-Jones G, Bloom FE (1981) Activity of norcpincphrine-containing locus coeruleus neurons in behaving rats anticipates fluctuations in the sleep-waking cycle. J Neurosci 1:876-886.

Baghdoyan HA, Rodrigo-Angulo ML, McCarley RW, Hobson JA (1987) A neuroanatomical gradient in the pontine tegmentum for the cholinoceptive induction of desynchronized sleep signs. Brain Res 414:245-261.

Baghdoyan HA, Lydic R, Callaway CW, Hobson JA (1989) The carbachol-induced enhancement of desynchronized sleep signs is dose dependent and antagonized by centrally administered atropine. Neuropsychopharmacology 2:67-79.

Berridge CW, Dunn AJ (1990) DSP-4-induced depletion of brain norepinephrine produces opposite effects on exploratory behavior 3 and 14 days after treatment. Psychopharmacology 100:504-508.

Bloor BD, Flacke WE (1982) Reduction of halothanc ancsthetic requirements by clonidine, an alpha-2 adrenergic agonist. Anesth Analg (Cleve) 61:741-745.

Buzsaki G, Leung LS, Vanderwolf $\mathrm{CH}$ (1983) Cellular bases of hippocampal EEG in the behaving rat. Brain Res Rev 6:139-171.

Buzsaki G, Bickford RG, Ponomareff G, Thal LJ, Mandel R, Gage FH (1988) Nucleus basalis and thalamic control of neocortical activity in the freely moving rat. J Neurosci 8:4007-4026.

De Sarro GB, Ascioti C, Froio F, Libri V, Nistico G (1987) Evidence that locus coeruleus is the site where clonidine and drugs acting at alpha-1 - and alpha-2-adrenoceptors affect sleep and arousal mechanisms. Br J Pharmacol 90:675-685.

De Sarro GB, Bagetta G, Libri V, Nistico G (1988) Microinfusion of clonidine and yohimbine into locus coeruleus alters EEG power spectrum: effects of aging and reversal by phosphatidylscrinc. Br J Pharmacol 95:1278-1286.

De Sarro GB, Bagetta G, Ascioti C, Libri V, Nistico G (1989) Effects of pertussis toxin on the behavioural and $E C O G$ spectrum changes induced by clonidine and yohimbine after their microinfusion into the locus coeruleus. Br J Pharmacol 96:59-64.

Diaz J, Elison G, Masouka D (1978) Stages of recovery from central norepinephrine lesions in enriched and impoverished environments: a behavioral and biochemical study. Exp Brain Res 31:117-130.

Egan TM, North RA (1985) Acetylcholine acts on $\mathrm{m}_{2}$-muscarinic receptors to excite rat locus coeruleus neurones. $\mathrm{Br} \mathrm{J}$ Pharmacol 85: 733-735.

El Mansari M, Sakai K, Jouvet M (1990) Responses of presumed cholinergic mesopontine tegmental neurons to carbachol microinjections in frecly moving cats. Brain Res 83:115-123.

Fink M, Irwin P (1981) CNS effects of clonidine in normal volunteers. Psychopharmacol Bull 17:16-17.

Flicker C, Geyer MA (1982) Behavior during hippocampal microinfusions. I. Norepinephrine and diversive exploration. Brain Res Rev 4:79-103.

Foote SL, Morrison JH (1987) Extrathalamic modulation of neocortical function. Annu Rev Neurosci 10:67-95.

Foote SL, Aston-Jones G, Bloom FE (1980) Impulse activity of locus coeruleus neurons in awake rats and monkeys is a function of sensory stimulation and arousal. Proc Natl Acad Sci USA 77:3033-3037.

Foote SL, Bloom FE, Aston-Jones G (1983) The nucleus locus coeruleus: new evidence of anatomical and physiological specificity. Physiol Rev 63:844-914. 
Gatti PJ, Hill KJ, Da Silva AMT, Norman WP, Gillis RA (1988) Central nervous system site of action for the hypotensive effect of clonidine in the cat. J Pharmacol Exp Ther 245:373-380.

Gnadt JW, Pegram GV (1986) Cholinergic brainstem mechanism of REM sleep in the rat. Brain Res 384:29-41.

Hilakivi I (1983) The role of $\beta$ - and $\alpha$-adrenoceptors in the regulation of the sleep-waking cycle in the cat. Brain Res 277:109-118.

Hobson JA, McCarley RW, Wyzinski PW (1975) Sleep cycle oscillation: reciprocal discharge by two brainstem neuronal groups. Science 189:55-58.

Hobson JA, Lydic R, Baghdoyan HA (1986) Evolving concepts of sleep cycle generation: from brain centers to neuronal populations. Behav Brain Sci 9:371-448.

Itil TM, Itil KZ (1983) Central mechanisms of clonidine and propranolol in man: quantitative pharmaco-EEG with antihypertensive compounds. Chest 83:411-416.

Jones BE, Bobillier P, Pin C, Jouvet M (1973) The effect of lesions of catecholamine-containing neurons upon monoamine content of the brain and EEG and behavioral waking in the cat. Brain Res 58:157177.

Jones BE, Harper ST, Halaris AF (1977) Effect of locus coeruleus lesions upon cerebral monoamine content, sleep-wakefulness states and the response to amphetamine in the rat. Brain Res 124:473-496.

Jouvet M (1972) The role of monoamines and acetylcholine containing neurons in the regulation of the sleep waking cycle. Ergeb Physiol 64: 166-307.

Kaukinen S, Pyykko K (1979) The potentiation of halothane anesthesia by clonidine. Acta Anaesthesiol Scand 23:107-111.

Kleinlogel H (1989) Effects of the selective $\alpha$-adrenoceptor blocker prazosin on EEG sleep and waking stages in the rat. Neuropsychobiology 21:100-103.

Laverty R, Taylor KM (1969) Behavioural and biochemical effects of 2-(2,6-dichlorophenylamino)-2-imidazoline hydrochloride (St 155) on the central nervous system. Br J Pharmacol 35:253-264.

Leonard CS, I.linas R (1988) Electrophysiology of thalamic-projecting cholinergic brainstem neurons and their inhibition by Ach. Soc Neurosci Abstr 14:297.

Lidbrink P (1974) The effects of lesions of the ascending noradrenaline pathways on sleep and waking in the rat. Brain Res 74:19-40.

Lidbrink P, Fuxe K (1973) Effect of intracerebral injections of 6-hydroxydopamine on sleep and waking in the rat. J Pharm Pharmacol 25:84-86.

Makela JP, Hilakivi IT (1986) Effect of alpha-adrenoceptor blockade on sleep and wakefulness in the rat. Pharmacol Biochem Behav 24: 613-616.

McCormick DA, Pape HC (1990) Noradrenergic and serotonergic modulation of a hyperpolarization-activated cation current in thalamic relay neurons. J Physiol (Lond) 431:319-342.

Nicoll RA, Malenka RC, Kauer JA (1990) Functional comparison of neurotransmitter receptor subtypes in mammalian central nervous system. Physiol Rev 70:513-565.

Pape HC, McCormick DA (1989) Noradrenaline and serotonin selectively modulate thalamic burst firing by enhancing a hyperpolarization-activated cation current. Nature 340:715-718.

Pellejero T, Monti JM, Baglietto J, Jantos H, Pazos S, Cicherski V, Hawkins M (1984) Effects of methoxamine and $\alpha$-adrenoceptor an- tagonists, prazosin and yohimbine, on the sleep-wake cycle of the rat. Sleep 7:356-372.

Ruggiero DA, Giuliano R, Anwar M, Stormetta R, Reis DJ (1990) Anatomical substrates of cholinergic-autonomic regulation in the rat. J Comp Neurol 292:1-53.

Sakai K, Mansari ME, Jouvet M (1990) Inhibition by carbachol microinjections of presumptive cholinergic $\mathrm{PGO}-$ on neurons in freely moving cats. Brain Res 527:213-223.

Segal DS, Mandell AJ (1970) Behavioral activation of rats during intraventricular infusion of norepinephrine. Proc Natl Acad Sci USA 66:289-293.

Shipley MT, Harris G, Williams J, Van Bockstaele E, Aston-Jones G, Ennis M (1990) Asymmetric orientation of locus coeruleus (LC) dendrites in the pericoeruleur region: biocytin-filled LC neurons in vitro. Soc Neurosci Abstr 16:1177.

Steriade M, McCarley RW (1990) Brainstem control of wakefulness and sleep. New York: Plenum.

Steriade M, Datta S, Pare D, Oakson G, Dossi RC (1990) Neuronal activities in brain-stem cholinergic nuclei related to tonic activation processes in thalamocortical systems. J Neurosci 10:2541-2559.

Svensson TH, Bunney BS, Aghajanian GK (1975) Inhibition of both noradrenergic and serotonergic neurons in brain by the alpha-adrenergic agonist clonidine. Brain Res 92:291-306.

Timo-Iaria C, Negrao N, Schmidek WR, Hoshino K, Lobato de Menezes CE, Da Rocha TL (1970) Phases and states of sleep in the rat. Physiol Behav 5:1057-1062.

U'Prichard DC, Reisine TD, Mason ST, Fibiger IIC, Yamamura III (1980) Modulation of rat brain alpha- and $\beta$-adrenergic receptor populations by lesion of the dorsal noradrenergic bundle. Brain Res 187:143-154.

Valentino RJ, Foote SL, Aston-Jones G (1983) Corticotropin-releasing factor activates noradrenergic neurons of the locus coeruleus. Brain Res 270:363-367.

Vanderwolf $\mathrm{CH}$ (1988) Cerebral activity and behavior: control by central cholinergic and serotonergic systems. Int Rev Neurobiol 30: 225-341.

Vanderwolf CH, Robinson TE (1981) Reticulo-cortical activity and behavior: a critique of the arousal theory and a new synthesis. Behav Brain Sci 4:459-514.

Vanni-Mercier G, Sakai K, Lin JS, Jouvet M (1989) Mapping of cholinoceptive brainstem structures responsible for the generation of paradoxical sleep in the cat. Arch Ital Biol 127:133-164.

Warsh JJ, Li PP, Godse DD, Cheung S (1981) Brain noradrenergic neuronal activity affects 3,4-dihydroxyphenylethyleneglycol (DHPG) levels. Life Sci 29:1303-1307.

Waterman A, Livingston A, Bouchenafa O (1988) Analgesic effects of intrathecally-applied alpha $a_{2}$-adrenoceptor agonists in conscious, unrestrained sleep. Neuropharmacology 27:213-216.

Zhang SP, Bandler R, Carrive P (1990) Flight and immobility evoked by excitatory amino acid microinjection within distinct parts of the subtentorial midbrain periaqueductal gray of the cat. Brain Res 520: $73-82$.

Zhang X, Abdel-Rahman AA, Wooles WR (1990) Selective sensitization by L-glutamate of baroreflex mediated bradycardia following microinjection into the rostral ventrolateral medulla. Brain Res 520: $141-150$. 